REKOGNISI: Jurnal Pendidikan dan Kependidikan

ISSN 2527-5259 Vol.1 No.1 Desember 2016

\title{
SIGNIFIKANSI KEPEMIMPINAN KEPALA SEKOLAH DALAM PENGELOLAAN SEKOLAH BERBASIS MANAJEMEN SEKOLAH
}

\author{
Siddik Siregar \\ SMA Negeri 1 Angkola Timur \\ Email: siddiksiregar67@yahoo.com
}

\begin{abstract}
ABSTRAK
Kepala sekolah adalah guru yang diberi tugas tambahan untuk memimpin suatu lembaga pendidikan formal. Kepala sekolah dituntut untuk senantiasa mengevaluasi kinerjanya dan meningkatkan efektivitas kinerjanya secara berkelanjutan agar manajemen berbasis sekolah sebagai paradigma baru yang diterapkan dapat berhasil. Kepemimpinan kepala sekolah dengan manajemen berbasis sekolah ditandai adanya kerjasama secara partisipatif dalam mengambil keputusan sekolah secara bersama-sama antara sekolah dan masyarakat. Ada empat prinsip dalam pengelolaan dengan manajemen berbasis sekolah yaitu prinsip ekuifinalitas, desentralisasi, sistem pengelolaan mandiri, dan inisiatif manusia.
\end{abstract}

Kata kunci: kepemimpinan kepala sekolah, manajemen berbasis sekolah, pengelolaan sekolah 


\begin{abstract}
A prinncipal is a teacher who were given the additional task to lead to lead a formal educational instituion. A principal is required to continually evaluate its performance and to improve the effetiveness of its performance on an ongoing basis in order to the school-based management as a new paradigm that can be applied successfully. Principal leadership with school-based management marked lack of cooperation in a participatory way in decision making schools jointly between the school and the community. There are four principles in the school-based management which are ekuifinality, desentralization, self-managing system and human initiative.
\end{abstract}

Key words: principal leadership, school-based management, school management

\title{
PENDAHULUAN
}

Undang-Undang No.20 tahun 2003 tentang Sistem Pendidikan Nasional menjelaskan bahwa pendidikan nasional berfungsi untuk mengembangkan kemampuan dan membentuk watak serta peradaban bangsa yang bermartabat dalam rangka mencerdaskan kehidupan bangsa. Disamping itu, UU No.20 juga menjelaskan bahwa pendidikan nasional bertujuan untuk mengembangkan potensi peserta didik agar menjadi manusia yang beriman dan bertakwa kepada Tuhan Yang Maha Esa, berakhlak mulia, sehat, berilmu, cakap, kreatif, mandiri, dan menjadi warga negara yang demokratis serta bertanggung jawab.

Dalam rangka menciptakan tujuan pendidikan Nasional diatas, sekolah merupakan salah satu lembaga yang bertanggung jawab untuk mencapainya. Keberadaan sekolah secara konsisten perlu melakukan upaya-upaya optimal dalam memberikan kontribusi positifnya mencerdaskan peserta didik sebagai kader bangsa secara berkesinambungan (sustainable) dalam koridor sistem pendidikan Nasional.

Pasca reformasi digulirkan, tuntutan perubahan telah menghantarkan menajemen pendidikan di Indonesia yang dulunya sentralistik menjadi desentralistik. Hal ini ditandai dengan munculnya Menajemen Berbasis Sekolah (School-Based Management). Sekolah diberikan keleluasaan untuk mengelola menajemennya berdasarkan kebutuhannya, demi tercapainya pengelolaan sekolah yang baik. Oleh karena itu, kepemimpinan yang profesional sangatlah dibutuhkan untuk mampu menghantarkan sekolah menjadi sekolah yang berkualitas.

Pemimpin dalam suatu lembaga sekolah adalah kepala sekolah. Kepala sekolah yang merupakan top manager haruslah memiliki kompetensi yang baik. Tanjung (2006: 8) menyatakan kompetensi yang harus dimiliki kepala sekolah 
antara lain: pengetahuan, keterampilan, dan nilai-nilai dasar yang direfleksikan kepala sekolah dalam kebijaksanaan berfikir dan bertindak secara konsisten yang memungkinnya menjadi kompeten dalam mengambil keputusan tentang penyediaan, pemanfaatan dan peningkatan potensi sumber daya untuk meningkatkan kualitas pendidikan di sekolah.

\section{PENGERTIAN KEPEMIMPINAN SEKOLAH}

Yukl (1981: 2) menyatakan leadership is interpersonal influence, exercised in a situation, an directed throught the communication process toward the attainment of a specified goal or goals. Kepala sekolah sebagai pemimpin di sekolah. Mulyasa (2004: 126) menyatakan kepala sekolah merupakan motor penggerak, penentu arah kebijakan sekolah, yang akan menentukan bagaimana tujuan-tujuan sekolah dan pendidikan pada umumnya direalisasikan. Sehubungan dengan manajemen berbasis sekolah, kepala sekolah dituntut untuk senantiasa meningkatkan efektifitas kinerja. Dengan begitu, menajemen berbasis sekolah sebagai paradigma baru pendidikan dapat memberikan hasil yang memuaskan.

Berdasarkan Peraturan Menteri Pendidikan Nasional Nomor 28 tahun 2010 tentang Penugasan Guru Sebagai Kepala Sekolah/Madrasah, menegaskan bahwa Kepala Sekolah/Madrasah adalah guru yang diberi tugas tambahan untuk memimpin Taman Kanak-Kanak/Raudhotul Athfal (TK/RA), Taman Kanak-Kanak Luar Biasa (TKLB), Sekolah Dasar/Madrasah Ibtidaiyah (SD/MI), Sekolah Dasar Luar Biasa (SDLB), Sekolah Menengah Pertama/Madrasah Tsanawiyah (SMP/MTs), Sekolah Menengah Pertama Luar Biasa (SMPLB), Sekolah Menengah Atas/Madrasah Aliyah (SMA/MA), Sekolah Menengah Kejuruan/Madrasah Aliyah Kejuruan (SMK/MAK), atau Sekolah Menengah Atas Luar Biasa (SMALB) yang bukan Sekolah Bertaraf Internasional (SBI) atau yang tidak dikembangkan menjadi SBI.

Sebagai pemimpin, kepala sekolah juga melaksanakan tugas layaknya seorang manajer. Paskalis, dkk (2012: 5) menyatakan dalam melaksanakan tugasnya sebagai manajer, kepala sekolah harus memiliki strategi yang tepat untuk memberdayakan tenaga kependidikan (staf dan tata usaha) melalui kerja sama, memberi kesempatan kepada para tenaga kependidikan untuk meningkatkan profesinya dan mendorong keterlibatan seluruh tenaga kependidikan dalam berbagai kegiatan yang menunjang program sekolah. Lebih lanjut lagi, Mulyasa (2009: 106) menyatakan tuntutan kemampuan dalam memberdayakan tenaga kependidikan di sekolah harus diwujudkan dalam pemberian arahan secara dinamis, pengkoordinasian tenaga kependidikan dalam pelaksanaan tugas, pemberian hadiah (reward) bagi mereka yang berprestasi dan pemberian hukuman (punishment) bagi yang kurang disiplin dalam melaksanakan tugas. 
Menurut Cunningham dan Paula (2003: 4) kepemimpinan kepala sekolah dapat dilihat kepada dua konteks yaitu kepemimpinan pendidik di dalam pembelajaran dan kepemimpinan kepala sekolah dalam mengelola sekolah. Cunningham dan Paula menyebutkan pememimpinan pendidikan dengan istilah $a$ school administrator dan kepemimpinan kepala sekolah sebagai a principil leadership. Cunningham dan Paula (2003: 4) menyatakan A school administrator is an educational leader who promotes the success of all students by facilitating the develompment, articulation, implementation, and stewardship of a vision of learning that is shared an supported by the school community and "A principil leadership have established proficencies that they believe to be critically important to principal leadership". Dengan kata lain, kepala sekolah bertindak sebagai pememimpin sekaligus manajer sekolah.

Berbagai pendapat di atas sejalan dengan Peraturan Menteri pendidikan Nasional nomor 13 tahun 2007, demi menunjang proses pengelolaan/manajerial kepemimpinan di sekolah, seorang kepala sekolah harus memiliki kompetensi yang telah ditetapkan dalam Permendiknas nomor 13 tahun 2007 tersebut. Ada 5 kompetensi yang harus dimiliki oleh seorang kepala sekolah, yaitu; kompetensi kepribadian, manajerial, kewirausahaan, supervisi dan sosial. Tabel 1 berikut petikan lampiran Permendiknas nomor 13 tahun 2007.

Tabel 1. Standar Kompetensi Kepala Sekolah

\begin{tabular}{|c|c|c|c|}
\hline No & $\begin{array}{c}\text { Dimensi } \\
\text { Kompetensi }\end{array}$ & & Kompetensi \\
\hline \multirow[t]{6}{*}{1} & \multirow[t]{6}{*}{ Kepribadian } & 1.1 & $\begin{array}{l}\text { Berakhlak mulia, mengembangkan budaya dan } \\
\text { tradisi akhlak mulia, dan menjadi teladan akhlak } \\
\text { mulia bagi komunitas di sekolah/madrasah. }\end{array}$ \\
\hline & & 1.2 & $\begin{array}{l}\text { Memiliki integritas kepribadian sebagai } \\
\text { pemimpin. }\end{array}$ \\
\hline & & 1.3 & $\begin{array}{lccc}\text { Memiliki keinginan yang kuat } & \text { dalam } \\
\text { pengembangan diri } & \text { sebagai } & \text { kepala } \\
\text { sekolah/madrasah. } & & & \end{array}$ \\
\hline & & 1.4 & $\begin{array}{l}\text { Bersikap terbuka dalam melaksanakan tugas } \\
\text { pokok dan fungsi. }\end{array}$ \\
\hline & & 1.5 & $\begin{array}{l}\text { Mengendalikan diri dalam menghadapi masalah } \\
\text { dalam pekerjaan sebagai kepala } \\
\text { sekolah/madrasah. }\end{array}$ \\
\hline & & 1.6 & $\begin{array}{l}\text { Memiliki bakat dan minat jabatan sebagai } \\
\text { pemimpin pendidikan. }\end{array}$ \\
\hline 2 & Manajerial & 2.1 & $\begin{array}{l}\text { Menyusun perencanaan sekolah/madrasah } \\
\text { untuk berbagai tingkatan perencanaan. }\end{array}$ \\
\hline
\end{tabular}




\begin{tabular}{|c|c|c|c|}
\hline No & $\begin{array}{c}\text { Dimensi } \\
\text { Kompetensi }\end{array}$ & \multicolumn{2}{|r|}{ Kompetensi } \\
\hline & & 2.2 & $\begin{array}{l}\text { Mengembangkan organisasi sekolah/madrasah } \\
\text { sesuai dengan kebutuhan. }\end{array}$ \\
\hline & & 2.3 & $\begin{array}{l}\text { Memimpin sekolah/madrasah dalam rangka } \\
\text { pendayagunaan sumber daya sekolah/madrasah } \\
\text { secara optimal. }\end{array}$ \\
\hline & & 2.4 & $\begin{array}{lrr}\text { Mengelola perubahan dan } & \text { pengembangan } \\
\text { sekolah/madrasah } & \text { menuju } & \text { organisasi } \\
\text { pembelajar yang efektif. } & & \end{array}$ \\
\hline & & 2.5 & $\begin{array}{l}\text { Menciptakan budaya dan iklim } \\
\text { sekolah/madrasah yang kondusif dan inovatif } \\
\text { bagi pembelajaran peserta didik. }\end{array}$ \\
\hline & & 2.6 & $\begin{array}{l}\text { Mengelola guru dan staf dalam rangka } \\
\text { pendayagunaan sumber daya manusia secara } \\
\text { optimal. }\end{array}$ \\
\hline & & 2.7 & 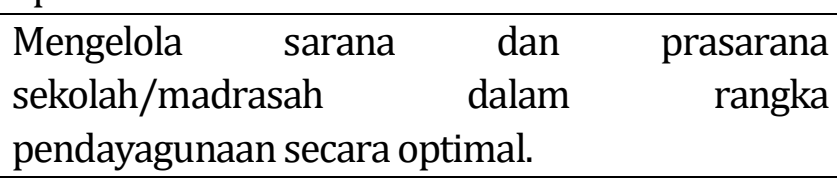 \\
\hline & & 2.8 & $\begin{array}{l}\text { Mengelola hubungan sekolah/madrasah dan } \\
\text { masyarakat dalam rangka pencarian dukungan } \\
\text { ide, sumber belajar, dan pembiayaan } \\
\text { sekolah/madrasah. }\end{array}$ \\
\hline & & 2.9 & $\begin{array}{l}\text { Mengelola peserta didik dalam rangka } \\
\text { penerimaan peserta didik baru, dan penempatan } \\
\text { dan pengembangan kapasitas peserta didik. }\end{array}$ \\
\hline & & 2.10 & $\begin{array}{l}\text { Mengelola pengembangan kurikulum dan } \\
\text { kegiatan pembelajaran sesuai dengan arah dan } \\
\text { tujuan pendidikan nasional. }\end{array}$ \\
\hline & & 2.11 & $\begin{array}{l}\text { Mengelola keuangan sekolah/madrasah sesuai } \\
\text { dengan prinsip pengelolaan yang akuntabel, } \\
\text { transparan, dan efisien. }\end{array}$ \\
\hline & & 2.12 & $\begin{array}{l}\text { Mengelola ketatausahaan sekolah/madrasah } \\
\text { dalam mendukung pencapaian tujuan } \\
\text { sekolah/madrasah. }\end{array}$ \\
\hline & & 2.13 & $\begin{array}{l}\text { Mengelola unit layanan } \\
\text { sekolah/madrasah dalam mendukung } \\
\text { pembelajaran dan kegiatan peserta didik di } \\
\text { sekolah/madrasah. }\end{array}$ \\
\hline & & 2.14 & $\begin{array}{l}\text { Mengelola sistem informasi sekolah/madrasah } \\
\text { dalam mendukung penyusunan program dan }\end{array}$ \\
\hline
\end{tabular}




\begin{tabular}{|c|c|c|c|}
\hline \multirow[t]{4}{*}{ No } & \multirow[t]{4}{*}{$\begin{array}{c}\text { Dimensi } \\
\text { Kompetensi }\end{array}$} & \multicolumn{2}{|r|}{ Kompetensi } \\
\hline & & \multicolumn{2}{|r|}{ pengambilan keputusan. } \\
\hline & & 2.15 & $\begin{array}{l}\text { Memanfaatkan kemajuan teknologi informasi } \\
\text { bagi peningkatan pembelajaran dan manajemen } \\
\text { sekolah/madrasah. }\end{array}$ \\
\hline & & 2.16 & $\begin{array}{l}\text { Melakukan monitoring, evaluasi, dan pelaporan } \\
\text { pelaksanaan program kegiatan } \\
\text { sekolah/madrasah dengan prosedur yang tepat, } \\
\text { serta merencanakan tindak lanjutnya. }\end{array}$ \\
\hline \multirow[t]{5}{*}{3} & \multirow[t]{5}{*}{ Kewirausahaan } & 3.1 & $\begin{array}{l}\text { Menciptakan inovasi yang berguna bagi } \\
\text { pengembangan sekolah/madrasah. }\end{array}$ \\
\hline & & 3.2 & $\begin{array}{l}\text { Bekerja keras untuk mencapai keberhasilan } \\
\text { sekolah/madrasah sebagai organisasi pembelajar } \\
\text { yang efektif. }\end{array}$ \\
\hline & & 3.3 & $\begin{array}{l}\text { Memiliki motivasi yang kuat untuk sukses dalam } \\
\text { melaksanakan tugas pokok dan fungsinya } \\
\text { sebagai pemimpin sekolah/madrasah. }\end{array}$ \\
\hline & & 3.4 & $\begin{array}{l}\text { Pantang menyerah dan selalu mencari solusi } \\
\text { terbaik dalam menghadapi kendala yang } \\
\text { dihadapi sekolah/madrasah. }\end{array}$ \\
\hline & & 3.5 & $\begin{array}{l}\text { Memiliki naluri kewirausahaan dalam mengelola } \\
\text { kegiatan produksi/jasa sekolah/madrasah } \\
\text { sebagai sumber belajar peserta didik. }\end{array}$ \\
\hline \multirow[t]{3}{*}{4} & \multirow[t]{3}{*}{ Supervisi } & 4.1 & $\begin{array}{l}\text { Merencanakan program supervisi akademik } \\
\text { dalam rangka peningkatan profesionalisme guru. }\end{array}$ \\
\hline & & 4.2 & $\begin{array}{l}\text { Melaksanakan supervisi akademik terhadap guru } \\
\text { dengan menggunakan pendekatan dan teknik } \\
\text { supervisi yang tepat. }\end{array}$ \\
\hline & & 4.3 & $\begin{array}{l}\text { Menindaklanjuti hasil supervisi akademik } \\
\text { terhadap guru dalam rangka peningkatan } \\
\text { profesionalisme guru. }\end{array}$ \\
\hline \multirow[t]{3}{*}{5} & \multirow[t]{3}{*}{ Sosial } & 5.1 & $\begin{array}{l}\text { Bekerja sama dengan pihak lain untuk } \\
\text { kepentingan sekolah/madrasah. }\end{array}$ \\
\hline & & 5.2 & $\begin{array}{lll}\text { Berpartisipasi dalam } & \text { kegiatan } & \text { sosial } \\
\text { kemasyarakatan. } & & \end{array}$ \\
\hline & & 5.3 & $\begin{array}{l}\text { Memiliki kepekaan sosial terhadap orang atau } \\
\text { kelompok lain. }\end{array}$ \\
\hline
\end{tabular}




\section{PENGERTIAN MANAJEMEN BERBASIS SEKOLAH}

Latar belakang munculnya Menajemen Berbasis Sekolah (MBS) tidak terlepas dari kinerja pendidikan di suatu negara berdasarkan sistem pendidikan yang ada sebelumnya. Di Hongkong misalnya, kemunculan MBS dilatarbelakangi kurang baiknya sistem pendidikan saat itu. Antara tahun 1960-an hingga 1970-an berbagai inovasi dilakukan melalui pengenalan kurikulum baru dan pendekatan metode pengajaran baru dalam rangka meningkatkan kualitas pendidikan, namun hasilnya tidak memuaskan. Nurkholis (2003: 16) menyatakan hal tersebut juga terjadi di banyak negara lain seperti Kanada, Amerika Serikat, Australia, Inggris, Prancis, Selandia Baru dan Indonesia. Ketidaktercapainya tujuan dari hasil perubahan tersebut, maka muncul berbagai reformasi seperti gerakan sekolah efektif (effective school) yang mencari dan mempromosikan karakteristik sekolahsekolah efektif. Ada gerakan anggaran sekolah mandiri (self-budgetting school) yang menekankan otonomi penggunaan sumber dana sekolah. Nurkholis (2003: 17) juga menyatakan gerakan perubahan itu ada yang menfokuskan pada desentralisasi otoritas dari kantor pendidikan pusat kepada aktivitas-aktivitas yang dipusatkan di sekolah seperti pengembangan kurikulum berbasis sekolah (school-based curriculum development), pengembangan staf berbasis sekolah (school-based staff development) dan bimbingan siswa berbasis sekolah (school-based student counseling) dan sebagainya.

Pada akhir tahun 1980-an berbagai bentuk MBS segera menjadi topik sentral dan menjadi strategi-strategi dalam reformasi pendidikan diberbagai belahan dunia. Ciri MBS adalah adanya kerjasama secara partisipatif dalam mengambil keputusan sekolah secara bersama-sama antara sekolah dan masyarakat.

Menajemen berbasis sekolah secara leksikal terdiri dari tiga kata, yaitu menajemen, berbasis dan sekolah. Menurut Nurkholis (2003: 18) manajemen adalah proses penggunaan sumber daya secara efektif untuk mencapai sasaran. Dalam Kamisa (1997: 64) berbasis kata dasarnya basis yang artinya dasar atau asas. Dalam Kamisa (1997: 482) sekolah adalah lembaga untuk belajar dan mengajar serta tempat menerima dan memberikan pelajaran.

Secara luas Wholstetter dan Susan menyatakan MBS adalah pendekatan politis untuk mendesain ulang organisasi sekolah dengan memberikan kewenangan dan kekuasaan kepada partisipan sekolah pada tingkat lokal guna memajukan sekolahnya. Partisipan lokal sekolah tak lain adalah kepala sekolah, guru, konselor, pengembang kurikulum, administrator, orang tua siswa, masyarakat sekitar dan siswa. 


\section{PRINSIP MANAJEMEN BERBASIS SEKOLAH}

Ada empat prinsip yang menjadi tolak ukur dalam pengelolaan sekolah yang berpedoman atau beracuan pada MBS. Nurkholis (2003: 52) menyatakan keempat prinsip tersebut antara lain:

1. Prinsip ekuifinalitas; warga sekolah dalam kaitan pengelolaan dapat mengelola sekolah secara mandiri, yang dipimpin oleh kepala sekolah. Dalam pengelolaan tersebut, menyesuaikan latar belakang situasi dan kondisi sekolah masingmasing.

2. Prinsip desentralisasi; bertujuan untuk menemukan masalah sekaligus menentukan solusi permasalahan untuk proses pengajaran dan pembelajaran.

3. Prinsip sistem pengelolaan mandiri; kemampuan manajerial kepala sekolah sebagai pemimpin di sekolah sangat penting sekali. Sekolah memiliki otonomi tertentu untuk mengembangkan tujuan pembelajaran, strategi manajemen, distribusi sumber daya manusia dan sumber daya lainnya, memecahkan masalah, dan mencapai tujuan berdasarkan kondisi mereka masing-masing".

4. Prinsip inisiatif manusia; perlunya mengenali potensi diri, potensi SDM yang dimiliki sekolah agar kepala sekolah sebagai leader yang baik mampu mengelola dan memberdayakan potensi-potensi yang sekolah miliki. Prinsip ini mengakui bahwa manusia bukanlah sumber daya yang statis, melainkan dinamis. Oleh karena itu, potensi sumber daya manusia harus selalu digali, ditemukan, dan kemudian dikembangkan".

\section{PERAN KEPALA SEKOLAH DALAM PELAKSANAAN MANAJEMEN BERBASIS SEKOLAH}

Kepala sekolah dituntut untuk memiliki kemampuan memimpin yang efektif. Efektifitas kepemimpinan kepala sekolah dalam konteks manajemen berbasis sekolah, fokus pada pengertian yang disampaikan oleh Fullan (2007: 30) yaitu There are at least three components or dimentions at stake in implementing any new program or policy: (1) the possible use of new or revised materials (instructional resources such as curiculum materials or or technologies), (2) the possible use of new teaching approaches (i.e. new teaching strategies or activities), (3) and the possible alteration of beliefs (e.g. pedagogical assumption and theories underlying particular new policies or programs).

Efektivitas kinerja kepala sekolah harus senantiasa ditingkatkan. Sagala (2006: 54) menyatakan ada enam hal yang harus dilakukan kepala sekolah dalam pengelolaan sekolah berdasarkan MBS demi terciptanya efektifitas kinerjanya, antara lain:

1. Kepala sekolah sebagai pendidik

Pendidik adalah orang yang mendidik, sedangkan mendidik diartikan memberikan latihan (ajaran, pimpinan) mengenai akhlak dan kecerdasan pikiran sehingga pendidikan dapat diartikan proses pengubahan sikap dan tata 
laku seseorang atau kelompok orang dalam usaha mendewasakan manusia melalui upaya pengajaran dan latihan. Sebagai seorang pendidik kepala sekolah harus mampu menanamkan, memajukan dan meningkatkan empat macam nilai, yaitu:

a. Mental, hal-hal yang berkaitan dengan sikap batin dan watak manusia.

b. Moral, hal-hal yang berkaitan dengan ajaran baik buruk mengenai perbuatan, sikap dan kewajiban atau moral.

c. Fisik, hal-hal yang berkaitan dengan kondisi jasmani atau badan, kesehatan dan penampilan manusia secara lahiriah.

d. Artistik, hal-hal yang berkaitan kepekaan manusia terhadap seni dan keindahan.

Ada dua hal pokok yang perlu diperhatikan oleh seorang kepala sekolah sebagai pendidik yaitu sasaran atau kepada siapa perilaku sebagai pendidik itu diarahkan dan bagaimana peranan sebagai pendidik itu dilaksanakan. Sasaran utamanya ada tiga yaitu para guru atau tenaga fungsional yang lain, tenaga administratif (staf) dan para siswa atau peserta didik. Di samping ketiga sasaran utama pelaksanaan peranan kepala sekolah sebagai pendidik, terdapat pula kelompok sasaran lain yang tidak kalah pentingnya yaitu organisasi orang tua siswa, organisasi siswa, dan organisasi para guru. Keberadaan organisasi orang tua siswa lebih banyak diperlukan untuk membantu dan mengatasi keperluan berbagai sumber daya dalam membina kehidupan kepala sekolah, baik berupa dana, sarana, jasa maupun pemikiran-pemikiran juga membantu pelaksanaan pembinaan kesiswaan, khususnya pelaksanaan program-program diluar kurikuler. Organisasi siswa diperlukan dalam usaha memberikan wadah bagi para siswa dalam menumbuhkan dan mengembangkan berbagai minat, bakat, dan kreativitas melalui program-program kokurikuler, maupun diluar kurikuler serta dalam usaha menunjang keberhasilan program kurikuler. Organisasi guru sebenarnya merupakan organisasi profesi, sebab di dalam organisasi terhimpun para guru yang mempunyai latar belakang pendidikan yang sama. Sebagai organisasi profesi ada dua hal pokok yang sangat penting menjadi acuan, yaitu sebagai salah satu wadah pembinaan dan pengembangan profesi sesuai dengan bidangnya.

2. Kepala sekolah sebagai manajer

Seorang manajer atau kepala sekolah hakikatnya adalah seorang perencana, organisator, pemimpin, dan seorang pengendali. Menurut Stoner ada delapan macam fungsi seorang manajer yang perlu dilaksanakan dalam suatu organsisi dan merupakan fungsi kepala sekolah juga yaitu:

a. Kepala sekolah bekerja dengan dan melalui orang lain (work with and through other people).

b. Kepala sekolah bertanggung jawab dan mempertanggungjawabkan (responsible and accountable). 
c. Waktu dan sumber yang terbatas, seorang kepala sekolah harus mampu menghadapi berbagai persoalan (managers balance competing goals and set priorities).

d. Kepala sekolah harus berpikir secara analistik dan konsepsional (must think analytically and conceptionally).

e. Kepala sekolah sebagai juru penengah (mediators).

f. Kepala sekolah sebagai politisi (politicians).

g. Kepala sekolah adalah seorang diplomat.

h. Kepala sekolah berfungsi sebagai pengmbil keputusan yang sulit (make difficult decisions).

Di samping itu, Longenecker dkk berpendapat bahwa berdasarkan hasil analisis kegiatan manajerial, mengidentifikasi adanya landasan utama fungsifungsi manajemen, yaitu:

a. Planning and decision making.

b. Organizing for effective performance.

c. Leading and motivating.

d. Controlling performance.

3. Kepala sekolah sebagai pemimpin

Kata "memimpin" memberikan arti memberikan bimbingan, menuntun, mengarahkan dan berjalan di depan (precede). Pemimpin berperilaku untuk membantu organisasi dengan kemampuan maksimal dalam mencapai tujuan. Kepemimpinan adalah satu kekuatan penting dalam rangka pengelolaan. Oleh sebab itu, kemampuan memimpin secara efektif merupakan kunci untuk menjadi seorang manajer yang efektif. Esensi kepemimpinan adalah kepengikutan (followership), kemauan orang lain atau bawahan untuk mengikuti keinginan pemimpin. Dengan kata lain, pemimpin tidak akan terbentuk tanpa bawahan.

Menurut Koontz kepala sekolah sebagai pemimpin harus mampu:

a. Mendorong timbulnya kemauan yang kuat dengan penuh semangat dan percaya diri para guru, staf dan siswa dalam melaksanakan tugas masingmasing.

b. Memberikan bimbingan dan mengarahkan para guru, staf dan para siswa serta memberikan dorongan memacu dan berdiri didepan demi kemajuan dan memberikan inspirasi sekolah dalam mencapai tujuan.

Kepala sekolah sebagai seorang pemimpin menurut H.G.Hicks dan C.R. Gullet mengatakan bahwa fungsi kepala sekolah sebagai pemimpin adalah:

a. Harus memberikan perlakuan yang sama terhadap orang-orang yang menjadi bawahannya yang dapat menciptakan semangat kebersamaan diantara guru, staf dan para siswa. 
b. Selalu memberikan sugesti kepada guru, staf dan siswa agar terpelihara semangat, rela berkorban, rasa kebersamaan dalam melaksanakan tugas masing-masing.

c. Kepala sekolah bertanggung jawab untuk memenuhi atau menyediakan dukungan yang diperlukan oleh para guru, staff, dan siswa baik berupa dana, peralatan, waktu, dan bahkan suasana yang mendukung.

d. Berperan sebagai katalisator, dalam arti mampu menimbulkan dan menggerakkan semangat baru guru, staf dan siswa dalam pencapaian tujuan yang telah ditetapkan.

e. Dapat menciptakan rasa aman di dalam lingkungan sekolah agar guru, staf dan siswa dalam melaksanakan tugasnya merasa aman.

f. Menjadi teladan dalam hal sikap dan penampilan.

g. Selalu memberikan penghargaan terhadap guru, staf dan siswa yang berprestasi.

4. Kepala sekolah sebagai administrator

Menurut Gorton, bagi kepala sekolah ada tiga alasan penting untuk mengetahui prinsip-prinsip dalam memberikan pelayanan pendidikan yaitu kepala sekolah dapat mengembangkan rencana yang belum memiliki pola organisasi, mengevaluasi dan memperbaiki struktur organisasi, dan membuat rekomendasi dan mengevaluasi rencana struktur yang diusulkan. Semua prinsip dan program pelayanan diorganisasikan sehingga semua aktivitas dapat dilaksanakan secara efektif dan efisien dengan tujuan akhir membantu mencapai tujuan sekolah. Sebagai administrator juga kepala sekolah hendaknya dapat mengalokasikan anggaran yang memadai bagi upaya peningkatan kompetensi guru yaitu dengan menghargai setiap guru yang berprestasi.

5. Kepala sebagai supervisor

Secara spesifik program supervise menurut Sestina meliputi: (a) membantu guru secara individual dan secara kelompok dalam memecahkan masalah pengajaran; (b) mengkoordinasikan seluruh usaha pengajaran menjadi perilaku edukatif yang terintegrasi dengan baik; (c) menyelenggarakan program latihan berkesinambungan bagi guru-guru; (d) mengusahakan alatalat yang bermutu dan mencukupi bagi pembelajaran; (e) membangkitkan dan memotivasi kegairahan guru yang kuat untuk mencapai prestasi kerja yang maksimal dan (f) membangun hubungan yang baik dan kerjasama antara sekolah, lembaga sosial dan instansi terkait serta masyarakat.

Kepala sekolah perlu melaksanakan kegiatan supervisi secara berkala untuk mengetahui sejauh mana guru mampu melaksanakan pembelajaran, yang dapat dilakukan melalui kegiatan kunjungan kelas untuk mengamati proses pembelajaran secara langsung, terutama dalam pemilihan dan penggunaan metode, media yang digunakan dan keterlibatan siswa dalam proses 
pembelajaran. Kegiatan supervisi tersebut, akan memberikan informasi tentang kelemahan sekaligus keunggulan guru dalam melaksanakan pembelajaran, tingkat penguasaan kompetensi guru yang bersangkutan, selanjutnya diupayakan solusi, Pembinaan dan tindak lanjut tertentu sehingga guru dapat memperbaiki kekurangan yang ada sekaligus mempertahankan keunggulannya dalam melaksanakan pembelajaran.

6. Kepala sekolah sebagai wirausaha

Dalam menerapkan prinsip-prinsip kewirausaan dihubungkan dengan peningkatan kompetensi guru, maka kepala sekolah seyogyanya dapat menciptakan pembaharuan, keunggulan komparatif, serta memanfaatkan berbagai peluang. Kepala sekolah dengan sikap kewirauhasaan yang kuat akan berani melakukan perubahan-perubahan yang inovatif di sekolahnya, termasuk perubahan dalam hal-hal yang berhubungan dengan proses pembelajaran siswa beserta kompetensi gurunya.

Dampak dari pelaksanaan tugas dan peran kepala sekolah, juga harus dipahami oleh kepala sekolah. Dengan kata lain, kepala sekolah harus mampu melihat kinerjanya dalam memahami dan menghayati Standar Pelayanan Minimal (SPM) dan melaksanakannya secara tepat, serta memahami lingkungan sekolah sebagai bagian dari sistem sekolah yang bersifat terbuka.

\section{SIMPULAN}

Manajemen berbasis sekolah adalah salah satu cara yang dilakukan oleh pemerintah terutama sekolah untuk mencapai fungsi dan tujuan pendidikan Nasional yaitu; berfungsi mengembangkan kemampuan dan membentuk watak serta peradaban bangsa yang bermartabat dalam rangka mencerdaskan kehidupan bangsa, bertujuan untuk berkembangnya potensi peserta didik agar menjadi manusia yang beriman dan bertakwa kepada Tuhan Yang Maha Esa, berakhlak mulia, sehat, berilmu, cakap, kreatif, mandiri, dan menjadi warga negara yang demokratis serta bertanggung jawab.

Kepala sekolah dalam MBS dituntut bukan hanya sebagai leader (pemimpin), akan tetapi juga sebagai manajer. Keahlian kepala sekolah dalam mengelola sekolah dalam MBS harus mampu melibatkan seluruh potensi yang ada dimiliki disekolah maupun luar sekolah, seperti masyarakat (komite sekolah). Selain itu kepala sekolah yang terpenting harus mampu menjadikan dirinya sebagai edukator (pendidik), karena memang jabatan kepala sekolah hanyalah berupa tugas tambahan, sebagai menajer yang mampu mengelola institusi pendidikannya, sebagai leader (pemimpin) yang mampu mengambil kebijaksanaan ataupun administrator, supervisor maupun wirausaha. 


\section{DAFTAR PUSTAKA}

Cunningham, W. G. dan Paula A Cordeiro. 2003. Educational Leadership, A Problem Based Approach. Boston: Pearson Education.

Fullan, M. 2007. The New Meaning of Educational Change. New York: Teachers College Press.

Kamisa, 1997. Kamus Lengkap Bahasa Indonesia. Surabaya: Kartika.

Kompilasi Perundangan Bidang Pendidikan. 2009. Undang-undang nomor 20 tahun 2003 tentang Sistem Pendidikan Nasional, Yogyakarta: Pustaka Yustisia.

Mulyasa, E. 2004. Menajemen Berbasis Sekolah. Bandung: Remaja Rosdakarya. 2009. Menjadi Kepala Sekolah Profesional. Bandung: Remaja Rosdakarya.

Nurkolis, 2003. Menajemen Berbasis Sekolah, Teori, Model dan Aplikasi Jakarta: Grasindo.

Paskalis, dkk. 2012. Kepemimpinan Kepala Sekolah Dalam MBS, Pent. Pontianak: FKIP Univ. Tanjung Pura.

Sagala, S. 2006. Administrasi Pendidikan. Bandung: Alfabeta.

Tanjung, A. R. 2006. Kepemimpinan Kepala Sekolah dalam Penerapan Menajemen Berbasis Sekolah Pada SMA Gunung Sindur Bogor. Skripsi. Jakarta: PPS UIN Syarif Hidayatullah.

Wholstetter, Priscilla dan Susan A. M. Assesment of School-Based Management, Studies of Education Reform, (http://www.ed. gov/pubs/ser/ SchBasedMgmt)

Yukl, G. A. 1981. Leadership in Organization. New Jersey: Prentice Hall Inc. 